\title{
Charging and coagulation of radioactive and nonradioactive particles in the atmosphere
}

\author{
Yong-ha Kim ${ }^{1}$, Sotira Yiacoumi ${ }^{1}$, Athanasios Nenes ${ }^{2,3}$, and Costas Tsouris ${ }^{1,4}$ \\ ${ }^{1}$ School of Civil and Environmental Engineering, Georgia Institute of Technology, Atlanta, Georgia 30332-0373, USA \\ ${ }^{2}$ School of Earth and Atmospheric Sciences, Georgia Institute of Technology, Atlanta, Georgia 30332-0340, USA \\ ${ }^{3}$ School of Chemical and Biomolecular Engineering, Georgia Institute of Technology, Atlanta, Georgia 30332-0100, USA \\ ${ }^{4}$ Oak Ridge National Laboratory, Oak Ridge, Tennessee 37831-6181, USA \\ Correspondence to: Costas Tsouris (tsourisc@ornl.gov)
}

Received: 4 August 2015 - Published in Atmos. Chem. Phys. Discuss.: 3 September 2015

Revised: 15 February 2016 - Accepted: 4 March 2016 - Published: 16 March 2016

\begin{abstract}
Charging and coagulation influence one another and impact the particle charge and size distributions in the atmosphere. However, few investigations to date have focused on the coagulation kinetics of atmospheric particles accumulating charge. This study presents three approaches to include mutual effects of charging and coagulation on the microphysical evolution of atmospheric particles such as radioactive particles. The first approach employs ion balance, charge balance, and a bivariate population balance model (PBM) to comprehensively calculate both charge accumulation and coagulation rates of particles. The second approach involves a much simpler description of charging, and uses a monovariate PBM and subsequent effects of charge on particle coagulation. The third approach is further simplified assuming that particles instantaneously reach their steady-state charge distributions. It is found that compared to the other two approaches, the first approach can accurately predict time-dependent changes in the size and charge distributions of particles over a wide size range covering from the free molecule to continuum regimes. The other two approaches can reliably predict both charge accumulation and coagulation rates for particles larger than about 0.04 micrometers and atmospherically relevant conditions. These approaches are applied to investigate coagulation kinetics of particles accumulating charge in a radioactive neutralizer, the urban atmosphere, and an atmospheric system containing radioactive particles. Limitations of the approaches are discussed.
\end{abstract}

\section{Introduction}

Atmospheric particles play an important role in airborne transport of contaminants, such as radionuclides. Contaminants emitted from anthropogenic sources (e.g., nuclear plant accidents) can be captured by background aerosols and are then transported together with pre-existing particles. Contaminant-laden particles can be deposited onto the ground by dry and wet deposition (primary contamination) and subsequently resuspended by wind or heat-driven convection and moved to other areas (secondary contamination). For instance, due to these atmospheric dispersion patterns, radioactive particles (e.g., $\left.{ }^{137} \mathrm{Cs}\right)$ released during the Fukushima accident were sampled in situ $150 \mathrm{~km}$ away from the emission site (Yamauchi et al., 2012), and also found in many places around the world (Hoeve and Jacobson, 2012). Similar dispersion patterns of radioactive particles were observed after the Chernobyl accident (Yoshenko et al., 2006a, b). These examples suggest that particle deposition, which is largely affected by aerosol microphysics, can determine the fate of contaminants during atmospheric transport. Thus, accurate understanding of the microphysical behavior of atmospheric particles is necessary to more accurately predict transport of contaminants (especially long-lived ones, such as ${ }^{137} \mathrm{Cs}$ ), as well as their potential environmental impacts.

The microphysical behavior of atmospheric particles is driven by such properties as charge and size (Fuchs, 1989; Pruppacher and Klett, 1997). Atmospheric particles can acquire charge via self-charging and diffusion charging. Selfcharging refers to charge accumulation caused by radioactive 
decay which typically leads to emission of electrons from particle surfaces. Diffusion charging is attributed to diffusion of ions from the surrounding atmosphere onto the surface of particles. Radioactive particles can be charged through these two charging mechanisms (Greenfield, 1956; Yeh et al., 1976; Clement and Harrison, 1992; Clement et al., 1995; Gensdarmes et al., 2001; Walker et al., 2010; Kweon et al., 2013; Kim et al., 2014, 2015) while natural atmospheric particles are typically charged by diffusion charging (Hoppel, 1985; Yair and Levin, 1989; Renard et al., 2013). Particle charging can modify not only the charge but also the size distribution because charge on the particles modifies their coagulation rate coefficients by generating electrostatic interactions (Fuchs, 1989; Tsouris et al., 1995; Chin et al., 1998; Taboada-Serrano et al., 2005). Coagulation of atmospheric particles can influence their charging because the concentration of atmospheric ions is affected by the particle size distribution (Yair and Levin, 1989), thereby modifying the diffusion charging rates of the particles. Also, particle coagulation can result in charge neutralization or accumulation on atmospheric particles (Alonso et al., 1998). These effects imply that particle coagulation can influence the particle charge distribution. Thus, particle charging and coagulation can mutually affect each other and simultaneously affect both charge and size distributions in the atmosphere.

Theoretical and experimental investigations have been performed to examine the charging of radioactive particles and background aerosols in the atmosphere. However, the effects of coagulation of particles on the charge distribution have been frequently neglected by assuming that the size distribution is constant while they are charged (Greenfield, 1956; Hoppel, 1985; Yair and Levin, 1989). The assumption may be valid if the particle concentration is low or the steadystate charge distribution is instantaneously attained (Hoppel, 1985; Renard et al., 2013; Kim et al., 2015). If the timescale for particle charging is longer than that for particle coagulation, the assumption may no longer be valid (Yair and Levin, 1989). Also, the effects of charging on the particle size distribution are frequently neglected in aerosol transport models involving microphysics of atmospheric particles. A possible reason for neglecting the charging effects may be that the steady-state mean charge of atmospheric particles may rarely affect their coagulation rates (Seinfeld and Pandis, 2006). However, neglecting electrostatic particle-particle interactions may increase uncertainty of prediction results if particles can acquire multiple elementary charges (e.g., radioactive particles). The simplified assumption of omitting electrostatic particle interactions may create uncertainty in transport predictions of radioactive particles. Hence, it may be necessary to take into account the mutual effects of particle charging and coagulation processes in predicting the behavior of atmospheric particles carrying radioactive contaminants.

Previous attempts to consider charging effects include Oron and Seinfeld (1989a, b), who developed sectional ap- proaches to simultaneously predict the behavior of charged and uncharged atmospheric particles. Laakso et al. (2002) developed a general dynamic equation, including charging and coagulation kinetics of atmospheric particles. Yu and Turco (2001) presented a kinetic approach that involves diffusion charging and particle coagulation. However, the validity of these approaches was not evaluated using analytical solutions. Alonso (1999) and Alonso et al. (1998) developed analytical and numerical approaches to estimate timedependent changes in the size distributions of singly charged and neutral particles; thus, these approaches cannot be used to investigate the coagulation kinetics of particles acquiring multiple elementary charges. Also, none of these approaches considered self-charging; therefore, the aforementioned approaches may be subject to error when they are used to simulate atmospheric dispersion of radioactive plumes.

Our study presents three approaches to simultaneously predict time-dependent changes of the charge and size distributions of radioactive and nonradioactive particles over a wide size range. Development, validity, application, and limitations of these approaches are discussed.

\section{Model development}

\subsection{Ion balance model}

Many atmospheric processes can generate and remove ions in air. Typical ion sources in the atmosphere involve natural and artificial radioactivity, as well as cosmic rays. Ions are generally removed by ion-ion recombination and ionparticle attachment. Changes in ion concentrations by these processes can be given by (Kim et al., 2015)

$$
\begin{aligned}
\frac{\mathrm{d} n_{\text {ion }}^{+}}{\mathrm{d} t} & =-n_{\text {ion }}^{+} \sum_{k} \sum_{j} \beta_{k, j}^{+} N_{k, j}-\alpha_{\mathrm{rc}} n_{\text {ion }}^{+} n_{\text {ion }}^{-}+q, \\
\frac{\mathrm{d} n_{\text {ion }}^{-}}{\mathrm{d} t} & =-n_{\text {ion }}^{-} \sum_{k} \sum_{j} \beta_{k, j}^{-} N_{k, j}-\alpha_{\mathrm{rc}} n_{\text {ion }}^{+} n_{\text {ion }}^{-}+q+q_{e},
\end{aligned}
$$

where $n_{\text {ion }}^{ \pm}$refers to the number concentrations of positive or negative ions, the indices $k$ and $j$ represent the size and number of elementary charges of particles, respectively, $\beta_{k, j}^{ \pm}$ is the attachment coefficient between a particle and an ion, $N_{k, j}$ is the number concentration of particles, $\alpha_{\mathrm{rc}}$ is the recombination coefficient of ions, and $t$ is time. The first two terms of the right-hand side (RHS) of Eqs. (1) and (2) represent the loss rate of ions due to ion-particle attachment and ion-ion recombination, respectively. The third term denotes the production rate of ion pairs, $q$ :

$q=q_{b}+q_{I}$,

where $q_{b}$ is the ion production rate by cosmic rays and natural radioactivity, and $q_{I}$ is the ion production rate by radionuclides released by nuclear events. Electrons released 
by radioactive decay are taken into account via the last term of Eq. (2). Changes in the ion concentrations may affect the electrical conductivity of the atmosphere, $\sigma_{\text {air }}$ (Harrison and Carslaw, 2003):

$\sigma_{\mathrm{air}}=e\left(\mu_{+} n_{\mathrm{ion}}^{+}+\mu_{-} n_{\mathrm{ion}}^{-}\right)$,

where $e$ is the electrical charge and $\mu_{ \pm}$is the mobility of positive or negative ions. In Eq. (4), the terms in the parentheses of the RHS represent polar air conductivities.

\subsection{Charge balance models}

Self-charging generally accumulates positive charge on the surface of particles, while diffusion charging adds both positive and negative charges, indicating that the charging mechanisms can compete with one another. For radioactive particles involved in beta decay, time-dependent changes in their charge distributions due to competition of the charging mechanisms can be expressed by (Clement and Harrison, 1992; Kim et al., 2015):

$$
\begin{aligned}
\frac{\mathrm{d} N_{k j}}{\mathrm{~d} t} & =A_{k, j-1} N_{k, j-1}-A_{k, j} N_{k, j}+\beta_{k, j-1}^{+} n_{\text {ion }}^{+} N_{k, j-1} \\
& -\beta_{k, j}^{+} n_{\text {ion }}^{+} N_{k, j}+\beta_{k, j+1}^{-} n_{\text {ion }}^{-} N_{k, j+1} \\
& -\beta_{k, j}^{-} n_{\text {ion }}^{-} N_{k, j},
\end{aligned}
$$

where $A$ is the radioactivity of the radioactive particles. In Eq. (5), self-charging is represented by terms that include $A$, while diffusion charging is represented by terms with $\beta_{k, j}^{ \pm}$. If the terms for self-charging are removed, Eq. (5) becomes identical to the charge balance model presented by Renard et al. (2013) who predicted electrification phenomena of aerosols in the real atmosphere. The mean value of the particle charge distributions can be given by

$$
\frac{\mathrm{d} J_{k}}{\mathrm{~d} t}=\frac{\mathrm{d}}{\mathrm{d} t}\left(\frac{\sum j N_{k j}}{\sum N_{k j}}\right) .
$$

The mean charge $J$ of the radioactive particles of size $k$ can also be approximated using a simple charge balance equation (Kim et al., 2015):

$$
\frac{\mathrm{d} J_{k}}{\mathrm{~d} t}=A_{k}+\beta_{k, J}^{+} n_{\text {ion }}^{+}-\beta_{k, J}^{-} n_{\text {ion }}^{-},
$$

where $A_{k}$ is the radioactivity of the size $k$ particles. Similarly to Eq. (5), the mean charge accumulation rate of the radioactive particles (Eq. 7) depends on the competition between self and diffusion charging. Equations (5) and (7) indicate that the net charge of beta-emitting radioactive particles converges to a steady state where self-charging balances diffusion charging. The timescale, $\tau$, needed to reach a steady state can be given by (Clement and Harrison, 1992)

$\tau=\frac{1}{\overline{\beta^{-}} n_{\text {ion }}^{-}}$, where $\overline{\beta^{-}}$is the mean attachment coefficient between negative ions and particles. At steady state, the mean charge of the radioactive particles can be approximated using (Clement et al., 1995)

$$
J_{k}=\left\{\begin{array}{lll}
y-\left(\frac{y(X-1)}{\exp (2 \lambda y)-1}\right), & \lambda y>0.22 & \text { (9a) } \\
y+\frac{X-1}{2 \lambda}, & \lambda y \leq 0.22 & \text { (9b) }
\end{array}\right\}
$$

$$
\text { with } \begin{aligned}
\lambda & =\frac{e^{2}}{8 \pi \varepsilon_{0} \varepsilon r_{k} k_{\mathrm{B}} T}, y=\frac{\varepsilon_{0} A_{k}}{e \mu_{-} n_{\text {ion }}^{0}}, n_{\text {ion }}^{0}=\sqrt{\frac{q}{\alpha}}, \\
X & =\frac{\mu_{+} n_{\text {ion }}^{+}}{\mu_{-} n_{\text {ion }}^{-}},
\end{aligned}
$$

where $\varepsilon_{0}$ is the vacuum permittivity, $\varepsilon$ is the dielectric constant of the air, $r$ is the radius of particles, $k_{\mathrm{B}}$ is the Boltzmann constant, $T$ is the temperature, and $n_{\text {ion }}^{0}$ is the mean ion concentration. Equation (9) suggests that the steady-state mean charge of beta-emitting radioactive particles is highly influenced by their size and decay rates, as well as the concentrations and mobilities of ions in air. The second term of the RHS of Eq. (9b) represents charge accumulated only by diffusion charging; thus, it can be used to approximate the steady-state mean charge of nonradioactive particles, such as background aerosols that are externally mixed with radionuclides.

\subsection{Population balance models}

\subsubsection{Bivariate population balance model}

A bivariate population balance model, expressed in terms of particle volume $x$ and charge $j$, can be used to predict effects of coagulation on time-dependent changes in the particle size and charge distributions. In the bivariate population balance model, the time evolution of the number densities of charged and uncharged particles, $n$, due to coagulation, can be given by (Zebel, 1958; Oron and Seinfeld, 1989a, b)

$$
\begin{aligned}
\frac{\partial n(x, j)}{\partial t} & =\frac{1}{2} \sum_{j^{\prime}=-\infty}^{\infty} \int_{0}^{x} F_{j^{\prime}, j-j^{\prime}}\left(x^{\prime}, x-x^{\prime}\right) n\left(x^{\prime}, j^{\prime}\right) \\
& n\left(x-x^{\prime}, j-j^{\prime}\right) \mathrm{d} x^{\prime}-\sum_{j^{\prime}=-\infty}^{\infty} \int_{0}^{\infty} F_{j, j^{\prime}}\left(x, x^{\prime}\right) \\
& n(x, j) n\left(x^{\prime}, j^{\prime}\right) \mathrm{d} x^{\prime},
\end{aligned}
$$

where $F$ is the coagulation frequency $\left(\mathrm{m}^{3} \mathrm{~s}^{-1}\right)$, which is also called the coagulation (rate) coefficient (Jacobson, 2005; Seinfeld and Pandis, 2006), and which can be obtained by multiplying the collision frequency and the collision efficiency. The two terms on the RHS of Eq. (10) represent the production and loss rates of charged and uncharged particles by coagulation, respectively. A numerical solution of Eq. (10) can 
be obtained through the discretization of the integral terms, respectively (Oron and Seinfeld, 1989a, b). Vanni (2000) tested several sectional approaches and showed that the approach of Kumar and Ramkrishna (1996) is simpler and more accurate than other tested approaches, and also preserves mass and number of particles. Thus, the sectional approach of Kumar and Ramkrishna (1996) was used in this study to discretize the integral terms of Eq. (10), leading to the following discretized form:

$$
\begin{aligned}
\frac{\mathrm{d} N_{k j}}{\mathrm{~d} t} & =\sum_{j^{\prime}=-\infty}^{\infty} \sum_{\substack{l, m \\
x_{k-1} \leq x_{l}+x_{m} \leq x_{k+1}}}^{l \geq m}\left(1-\frac{1}{2} \delta_{l, m}\right) \\
& \eta_{l, m} F_{l, m, j-j^{\prime}, j^{\prime}} N_{l, j-j^{\prime}} N_{m, j^{\prime}} \\
& -\sum_{j^{\prime}=-\infty}^{\infty} \sum_{l=1}^{M} F_{k, l, j, j^{\prime}} N_{k, j} N_{l, j^{\prime}}
\end{aligned}
$$

where indices $l$ and $m$ refer to the size bins, $\delta$ is the Kronecker delta, $\eta_{l, m}$ is a property distribution factor between two size bins given by Kumar and Ramkrishna (1996), and $M$ is the total number of the size bins. If coagulation is induced by thermal energy (i.e., Brownian coagulation), the Brownian collision frequency $\beta^{\mathrm{Br}}\left(\mathrm{m}^{3} \mathrm{~s}^{-1}\right)$, which is also called the Brownian collision kernel (Jacobson, 2005), is given by (Fuchs, 1989)

$$
\begin{aligned}
& \beta_{k l}^{\mathrm{Br}}=4 \pi\left(r_{k}+r_{l}\right)\left(D_{\mathrm{p}, k}+D_{\mathrm{p}, l}\right) \\
& \left(\frac{r_{k}+r_{l}}{r_{k}+r_{l}+\sqrt{g_{k}^{2}+g_{l}^{2}}}+\frac{4\left(D_{\mathrm{p}, k}+D_{\mathrm{p}, l}\right)}{\left(r_{k}+r_{l}\right) \sqrt{\bar{v}_{\mathrm{p}, k}^{2}+\bar{v}_{\mathrm{p}, l}^{2}}}\right)^{-1},
\end{aligned}
$$

where $D_{\mathrm{p}}$ is the particle diffusion coefficient, $g$ is the particle mean traveling distance, and $\bar{v}_{\mathrm{p}}$ is the particle thermal speed in air. Coagulation of charged particles is influenced by electrostatic particle-particle interactions. This effect can be accounted for by multiplying the collision frequency with the collision efficiency, $\alpha^{\mathrm{Br}}$, which is also called the coalescence efficiency (Fuchs, 1989; Jacobson, 2005; Seinfeld and Pandis, 2006):

$\alpha_{k l}^{\mathrm{Br}}=\frac{u}{e^{u}-1}$

with $u=\frac{j_{k} j_{l} e^{2}}{4 \pi \varepsilon_{0} \varepsilon\left(r_{k}+r_{l}\right) k_{\mathrm{B}} T}$.

In Eq. (13), $u$ indicates the relative importance between electrostatic potential energy and thermal energy in coagulation.

\subsubsection{Monovariate population balance model}

The time evolution of the size distribution of particles can be estimated using a monovariate population balance model, with only the particle volume as the variable (Kumar and
Ramkrishna, 1996):

$$
\begin{aligned}
\frac{\mathrm{d} N_{k}}{\mathrm{~d} t} & =\sum_{\substack{l, m \\
x_{k-1} \leq x_{l}+x_{m} \leq x_{k+1}}}^{l \geq m}\left(1-\frac{1}{2} \delta_{l, m}\right) \eta_{l, m} F_{l, m} N_{l} N_{m} \\
& -\sum_{l=1}^{M} F_{k, l} N_{k} N_{l} .
\end{aligned}
$$

The coagulation frequency can be simply corrected using the mean charge of particles. However, the collision efficiency computed with the mean charge can be different from that with the particle charge distributions (Matsoukas, 1997). To include effects of the particle charge distributions on the coagulation frequency, Eq. (13) can be replaced by the average collision efficiency $\bar{\alpha}$ (Clement et al., 1995), which involves interaction of all charged particles of size $k$ with any charged particles of size $l$.

$\bar{\alpha}_{k l}^{\mathrm{Br}}=1+\frac{\sum_{j_{k} j_{l} \neq 0} N_{k, j_{k}} N_{l, j_{l}}\left(\alpha_{k l}^{\mathrm{Br}}-1\right)}{\sum_{j_{k}} N_{k, j_{k}} \sum_{j_{l}} N_{l, j_{l}}}$.

The particle charge distributions needed to calculate $\bar{\alpha}^{\mathrm{Br}}$ can be obtained by assuming a Gaussian distribution:

$N_{k j}=\frac{\sum_{j} N_{k, j}}{\sqrt{2 \pi} \sigma_{k}} \exp \left(-\frac{\left(j-J_{k}\right)^{2}}{2 \sigma_{k}^{2}}\right)$

with $\sigma^{2}=y+\frac{1}{2 \lambda}$.

\subsection{Approaches to couple particle charging with coagulation kinetics}

Figure 1 shows three approaches which can be used to predict the time evolution of the charge and size distributions of particles in the atmosphere. All the approaches can be used to simulate charging and coagulation kinetics of atmospheric particles carrying contaminants, including radioactive particles. Approach 1 is a rigorous scheme that simultaneously computes both charge accumulation and coagulation rates of particles using the ion balance model (Eqs. 1 and 2), the charge balance model (Eq. 5), and the bivariate population balance model (Eq. 11). Approach 2 is a simplified scheme of Approach 1, which can be used to predict the particle charge distribution using the mean charge of particles (Eq. 7) and the Gaussian distribution (Eq. 16). In order to easily simulate the coagulation of charged particles, Approach 2 employs the monovariate population balance model (Eq. 14) that corrects the collision frequency using the average collision efficiency (Eq. 15). Approach 2 can be simplified to Approach 3 by assuming that charge accumulation rates of particles instantaneously reach a steady state, with a timescale based on 5 times larger than $\tau$ from Eq. (8). The steady-state particle charge distribution can be approximated by Eqs. (9) and (16). In Approach 3, the collision frequency is multiplied by the average collision efficiency to include the 


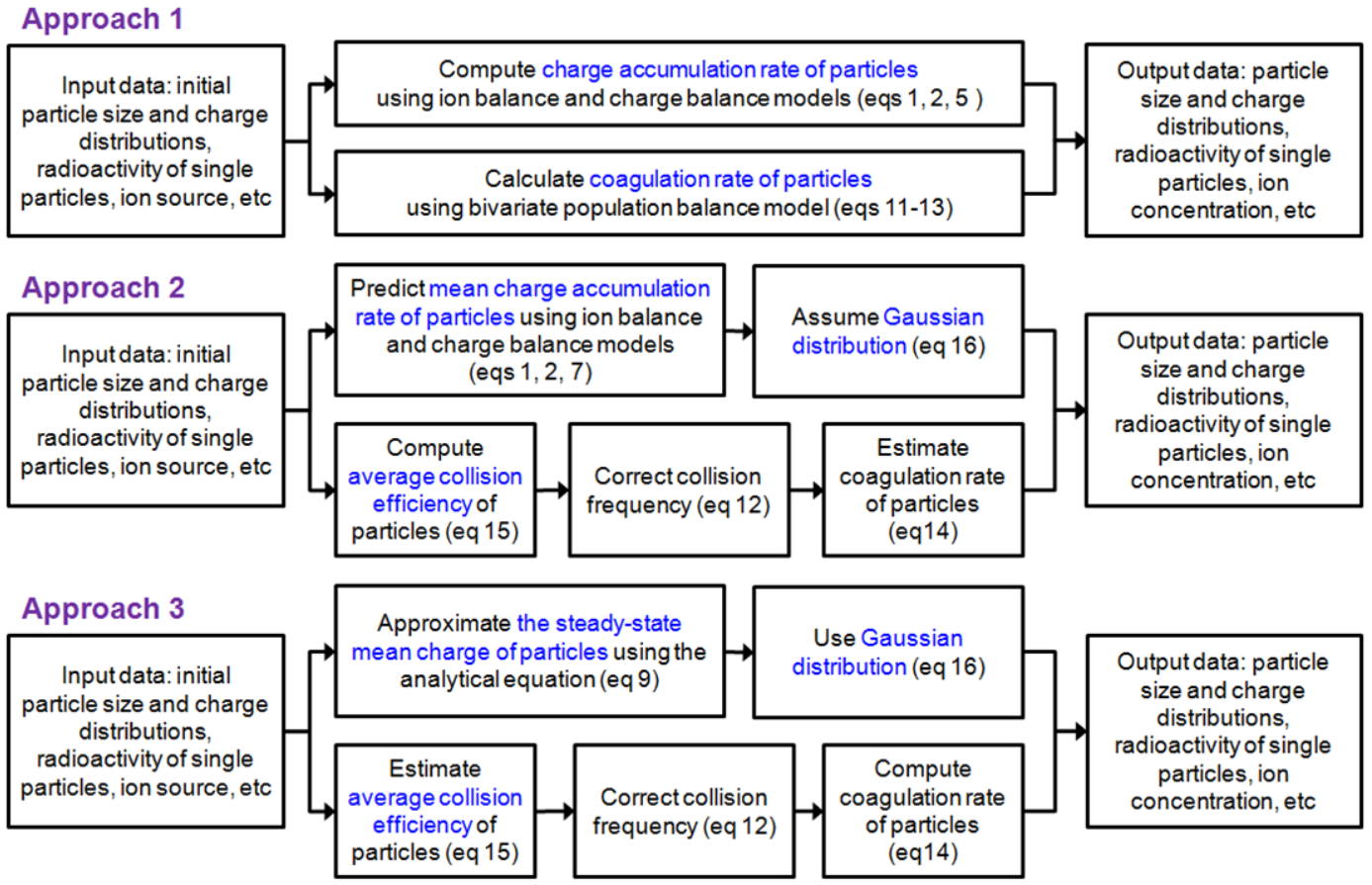

Figure 1. Three approaches to predict time-dependent changes in the particle size and charge distributions in the atmosphere.

influence of electrostatic forces on coagulation. In this work, polarization of particles is not taken into account.

\section{Results and discussion}

\subsection{Methods to simulate particle charging}

The three approaches attained above employ different methods to simulate charging of particles. These methods were evaluated by comparing their prediction results with measurements obtained using radioactive charge neutralizers (Liu and Pui, 1974; Wiedensohler and Fissan, 1991; Alonso et al., 1997) and radioactive particles (Gensdarmes et al., 2001). Initial conditions for the simulations were determined from the measurements. The properties of ions observed during the measurements are shown in Table 1. For the measurements providing the values of ion mass, $\beta_{k, j}^{ \pm}$was calculated using Fuchs (1963) and Hoppel and Frick (1986). However, the mass of ions was not measured during the experiments performed by Gensdarmes et al. (2001). In these experiments, $\beta_{k, j}^{ \pm}$was estimated using analytical equations given by Gunn (1954) and Harrison and Carslaw (2003).

\subsubsection{Diffusion-charging mechanism}

Figure 2 shows the steady-state charge distributions of nonradioactive particles over a wide size range. Here, the particles were charged by the diffusion charging mechanism. For particles larger than approximately $0.04 \mu \mathrm{m}$ in diameter, the prediction results of all approaches were in good agreement with the measurements (Fig. 2a and b). Below $0.04 \mu \mathrm{m}$ particle size, Approach 1 accurately forecasted the particle charge distributions, but Approaches 2 and 3 underestimated the number concentrations of the negatively charged particles (Fig. 2a) although the mean charge values of the particles given by all approaches were comparable. Similar discrepancies were observed for the number concentrations of the positively charged particles smaller than about $0.025 \mu \mathrm{m}$ (not shown).

Analysis of the discrepancies suggests that they originate from the standard deviation involved in the Gaussian distribution (Eq. 16). At a given temperature, the width of the particle charge distributions can be significantly influenced by three parameters: the particle size, ion mass, and ion mobility (Wiedensohler and Fissan, 1991). In Approaches 2 and 3, however, the effects of the ion properties are not involved, so particle size primarily drives the standard deviation, which can differ from what Approach 1 gives. When Approaches 2 and 3 used the standard deviation values obtained by Approach 1 , their simulation results became closer to the measurements, although the discrepancies are still seen for negatively and positively charged particles smaller than about $0.02 \mu \mathrm{m}$.

\subsubsection{Competition of self-charging and diffusion-charging mechanisms}

In our previous work (Kim et al., 2014, 2015), it has been shown that Approaches 1 and 3 can reliably simulate charg- 
Table 1. Properties of ions used for experimental observations.

\begin{tabular}{lrrrrrr}
\hline References & \multicolumn{2}{c}{ Positive ions } & & \multicolumn{2}{c}{ Negative ions } \\
\cline { 2 - 3 } \cline { 5 - 6 } & $\begin{array}{r}\text { Mass } \\
\text { (AMU) }\end{array}$ & $\begin{array}{r}\text { Mobility } \\
\left(\mathrm{cm}^{2} \mathrm{~V}^{-1} \mathrm{~s}^{-1}\right)\end{array}$ & & $\begin{array}{r}\text { Mass } \\
(\text { AMU) }\end{array}$ & $\begin{array}{r}\text { Mobility } \\
\left(\mathrm{cm}^{2} \mathrm{~V}^{-1} \mathrm{~s}^{-1}\right)\end{array}$ \\
\hline Alonso et al. (1997) & 150 & 1.15 & & 80 & 1.65 \\
Liu and Pui (1974)* & 140 & 1.4 & & 101 & 1.6 \\
Wiedensohler and Fissan (1991) & 140 & 1.4 & & 101 & 1.6 \\
Gensdarmes et al. (2001) & - & 1.19 & & - & 1.54 \\
\hline
\end{tabular}

* The properties of ions were obtained from Wiedensohler and Fissan (1991), who used a radioactive neutralizer similar to that employed by Liu and Pui (1974).
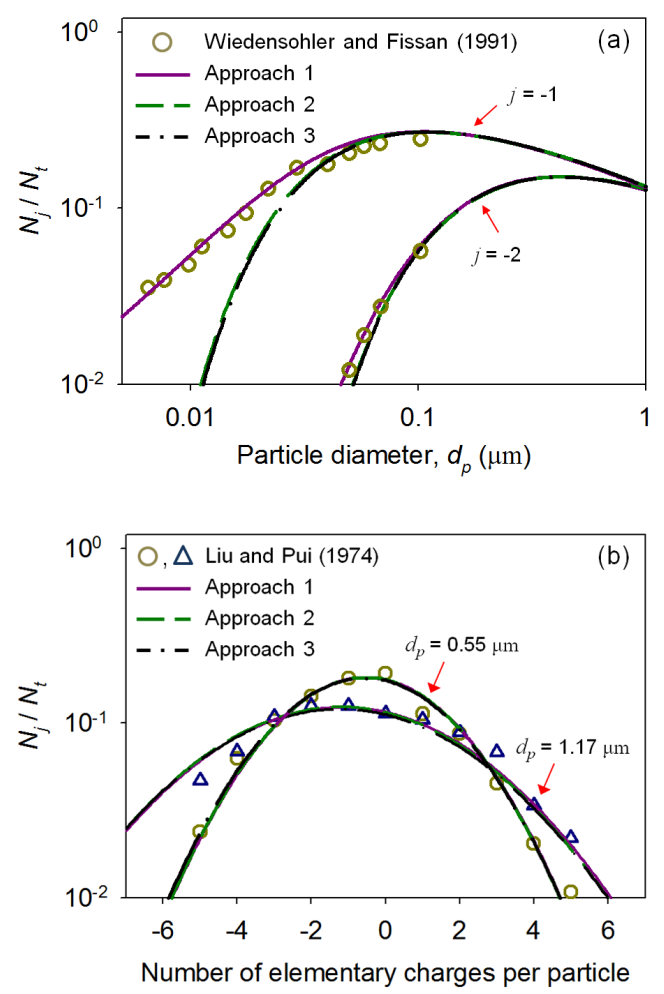

Figure 2. Steady-state charge distributions of particles capturing positive and negative ions. The symbols represent the measurements of the charge distributions of particles.

ing of radioactive particles. Thus, in this study, we focused on evaluating the validity of Approach 2 with the experiments of Gensdarmes et al. (2001) who measured the charge distributions of ${ }^{137} \mathrm{Cs}$ particles under various ionizing conditions. Ionizing rates of air molecules were estimated using a linear energy transfer equation for energetic electrons emitted by beta decay (Kim et al., 2015). Results of Approach 1 were included as a reference.

Figure 3 shows the charge accumulation on radioactive particles under two ionizing conditions: $q_{I}=3.7 \times$ $10^{8} \mathrm{~m}^{-3} \mathrm{~s}^{-1}$ and $q_{I}=7.1 \times 10^{6} \mathrm{~m}^{-3} \mathrm{~s}^{-1}$. Approach 2 predictions are in good agreement with observations and Ap-

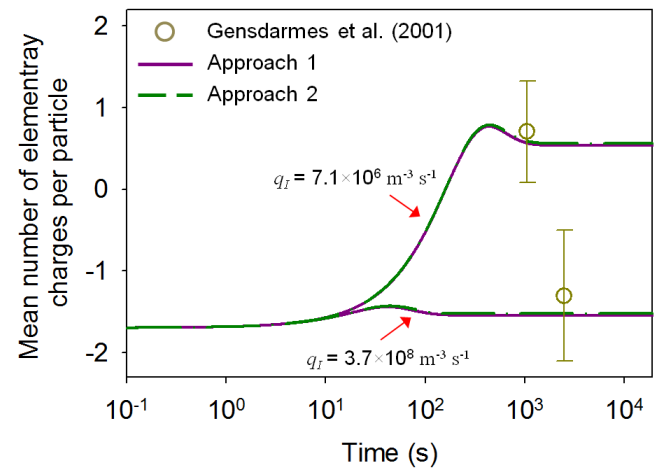

Figure 3. Charge accumulation on ${ }^{137} \mathrm{Cs}$ particles under two ionizing conditions: $q_{I}=7.1 \times 10^{6} \mathrm{~m}^{-3} \mathrm{~s}^{-1}$ and $q_{I}=3.7 \times$ $10^{8} \mathrm{~m}^{-3} \mathrm{~s}^{-1}\left(d_{\mathrm{p}}=0.82 \mu \mathrm{m} ; A_{\mathrm{Cs}-137}=12.8 \mathrm{mBq}\right)$. The symbols represent the mean value of the particle charge distributions measured by Gensdarmes et al. (2001).

proach 1 values. During the measurements, the self-charging rate of the radioactive particles was constant because of the long half-life of ${ }^{137} \mathrm{Cs}$ (approximately 30 years), suggesting that changes in their charge accumulation rates may be dominated by diffusion charging rates. The ion concentrations in air can rapidly increase at the high ionizing rate considered, suggesting that the diffusion charging rate of the ${ }^{137} \mathrm{Cs}$ particles quickly increased and then became comparable to their self-charging rate (Eq. 7). The charge accumulation on the radioactive particles promptly reached a steady-state value, and the particle charge distribution was similar to the initial condition (Fig. 4). In contrast, the time required to reach the steady-state value was much longer at the low ionizing rate considered; hence, the particle charge distribution shifted to the right (see Fig. 4), i.e., more positive charge. The agreement observed in Fig. 4 between simulation results by Approach 2 and experimental data by Gensdarmes et al. (2001) suggests that Approach 2 can accurately forecast the competition between self and diffusion charging on submicron particles carrying radionuclides, and precisely predict the particle charge distributions. 
Table 2. Timescales required for particles to reach steady-state charge.

\begin{tabular}{|c|c|c|c|c|c|c|}
\hline $\begin{array}{l}\text { Charging } \\
\text { mechanism }\end{array}$ & $\begin{array}{r}\text { Particle } \\
\text { diameter } \\
(\mu \mathrm{m})\end{array}$ & $\begin{array}{r}\text { Steady-state mean } \\
\text { ion concentration } \\
\left(\mathrm{m}^{-3}\right)\end{array}$ & $\begin{array}{r}\tau(\mathrm{s}) \\
\text { (Eq. 8) }\end{array}$ & $\begin{array}{r}\text { Numerical } \\
\text { timescale }(\mathrm{s}) \\
\text { (Approach } 1 \text { or } 2)\end{array}$ & $\begin{array}{r}\text { Timescale } \\
\text { from } \\
\text { measurements (s) }\end{array}$ & Reference \\
\hline \multirow[t]{4}{*}{ Diffusion charging } & 0.0071 & $8.0 \times 10^{12}$ & 0.04 & $0.2-0.4$ & 0.3 & Alonso et al. (1997) \\
\hline & 0.0070 & $2.0 \times 10^{13}$ & 0.02 & $0.2-0.4$ & 0.3 & \\
\hline & 0.0027 & $8.0 \times 10^{12}$ & 0.04 & $0.2-0.4$ & 0.3 & \\
\hline & 0.0026 & $2.0 \times 10^{13}$ & 0.02 & $0.2-0.4$ & 0.3 & \\
\hline \multirow[t]{4}{*}{ Diffusion charging and self-charging } & 0.82 & $2.1 \times 10^{9}$ & 171.1 & $>1000$ & - & Gensdarmes et al. (2001) \\
\hline & 0.82 & $1.5 \times 10^{10}$ & 23.6 & $>200$ & - & \\
\hline & 1.05 & $7.6 \times 10^{8}$ & 471.6 & $>3000$ & - & \\
\hline & 1.05 & $7.0 \times 10^{9}$ & 51 & $>500$ & - & \\
\hline
\end{tabular}

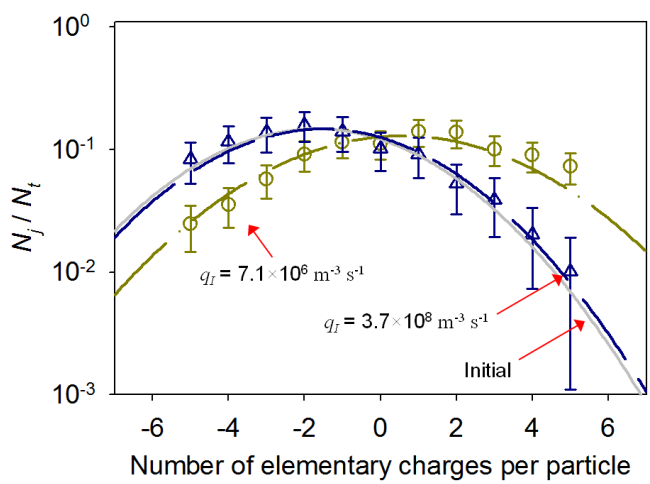

Figure 4. Charge distributions of ${ }^{137} \mathrm{Cs}$ particles under two ionizing conditions: $q_{I}=7.1 \times 10^{6} \mathrm{~m}^{-3} \mathrm{~s}^{-1}$ and $q_{I}=3.7 \times 10^{8} \mathrm{~m}^{-3} \mathrm{~s}^{-1}$ $\left(d_{\mathrm{p}}=0.82 \mu \mathrm{m} ; A_{\mathrm{Cs}-137}=12.8 \mathrm{mBq}\right)$. The prediction results of Approach 2 were compared with the measurements of Gensdarmes et al. (2001).

\subsubsection{Timescale to reach steady-state charge accumulation rate}

To evaluate the steady-state assumption of particle charging for atmospheric conditions, the timescale for reaching steady state (Eq. 8) is evaluated with Approaches 1 and 2. Figure 5 shows time-dependent changes in the concentrations of negatively charged particles under two different initial conditions of Alonso et al. (1997) who measured the charge distributions of particles of a few nanometers. All particles were initially uncharged or negatively charged. Because the particle size was very small, Approach 1 was used to predict the time evolution of the particle concentrations. As time elapsed, the initially uncharged particles became negatively charged by capturing negative ions. The diffusion of positive ions led to the discharging of the initially negatively charged particles. For the initial conditions used, the charging and discharging rates of the particles reached a steady state after approximately $0.2 \mathrm{~s}$, respectively. This charging and/or discharging behavior predicted by Approach 1 is in good agreement with the measurements of Alonso et al. (1997). However, the timescales obtained from Eq. (8) are shorter than

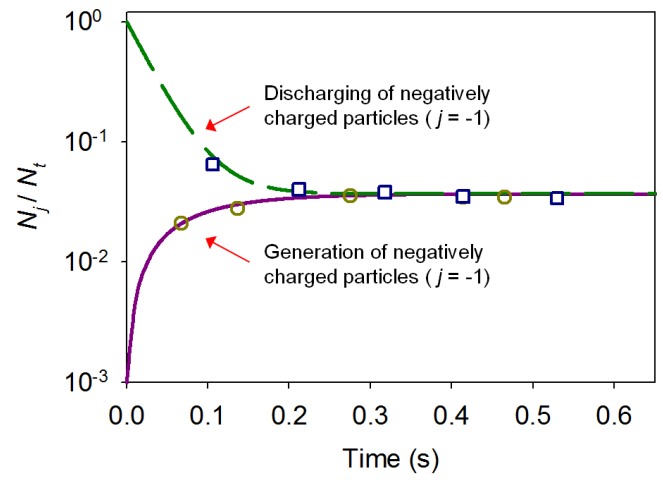

Figure 5. Timescale to reach steady-state charge accumulation rates of $0.0071 \mu \mathrm{m}$ nanoparticles. The lines are the simulation results of Approach 1. The symbols are the measurements of Alonso et al. (1997). Charging timescales were estimated using Eq. 8 ( $\tau_{\text {charging }}=0.042 \mathrm{~s}$ and $\left.\tau_{\text {discharging }}=0.017 \mathrm{~s}\right)$, as well as Approach 1 and the measurements.

the prediction results, as well as the measurements, because Approach 1 and the observations provided exact timescales, while $\tau$ in Eq. (8) is a scaling parameter. Similar results were also obtained for different initial conditions, as well as for the ${ }^{137}$ Cs particles (see Table 2).

Equation (8) is based on the assumptions that (i) $X \approx 1$, (ii) all particles are initially uncharged, and (iii) the ion concentrations are constant (Clement and Harrison, 1992). As seen in Fig. 6, when all the assumptions were applied, the diffusion charging rate of the radioactive particles became $-8.1 \times 10^{-3} \mathrm{~s}^{-1}$ at the timescale provided by Eq. (8), which corresponds to approximately $63 \%$ of the steady-state selfcharging rate. If the timescale is increased by a factor of five, the diffusion charging rate reaches about $99 \%$ of the steady-state self-charging rate. Similar results were obtained for other cases with radioactive particles. Thus, Eq. (8) is valid if the assumptions can be used, and a reliable timescale to reach a steady state (e.g., $99 \%$ ) can be obtained by multiplying the equation by a factor of 5 . However, because the assumptions cannot be used in typical atmospheric conditions, such as $X \neq 1$ (Harrison and Carslaw, 2003), the steady-state 


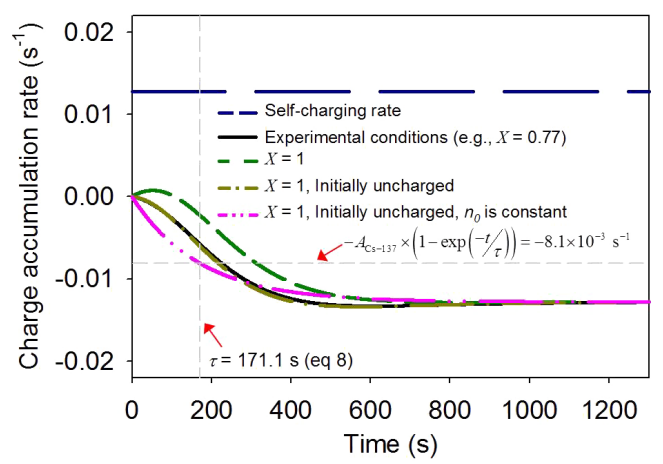

Figure 6. Charge accumulation rate of ${ }^{137} \mathrm{Cs}$ particles for each charging mechanism $\left(d_{\mathrm{p}}=0.82 \mu \mathrm{m} ; A_{\mathrm{Cs}-137}=12.8 \mathrm{mBq} ; q_{I}=\right.$ $\left.7.1 \times 10^{6} \mathrm{~m}^{-3} \mathrm{~s}^{-1}\right)$. The assumptions used in Eq. (8) were applied to evaluate the validity of the equation. $A_{\mathrm{Cs}-137}$ corresponds to the self-charging rate of the radioactive particles.

assumption of Approach 3 should be evaluated using Approaches 1 or 2 .

So far, we have evaluated the validity of the methods used in the three approaches to predict charge accumulation on atmospheric particles. The evaluation results suggest that the method employed in Approach 1 can accurately simulate charging of particles in the free molecule $\left(d_{\mathrm{p}}<0.01 \mu \mathrm{m}\right)$, transition $\left(d_{\mathrm{p}}=0.01-0.2 \mu \mathrm{m}\right)$, and continuum $\left(d_{\mathrm{p}}>0.2 \mu \mathrm{m}\right)$ regimes. The methods used in Approaches 2 and 3 can reliably forecast charging rate of atmospheric particles larger than $0.04 \mu \mathrm{m}$.

\subsection{Validity of the three approaches to couple particle charging with coagulation}

\subsubsection{Bivariate population balance model for approach 1}

Based on the numerical approach of Alonso et al. (1998), Alonso (1999) suggested an analytical approach to simultaneously investigate charging and coagulation kinetics of nonradioactive particles, smaller than $0.02 \mu \mathrm{m}$ in diameter. Results of the analytical approach agreed well with those of the numerical approach, but the applicability of the analytical and numerical approaches may be limited as discussed in the Introduction section. The analytical approach, however, was found to be useful to validate numerical solutions of population balance equations including diffusion charging and coagulation (Alonso, 1999). In this study, the analytical approach of Alonso (1999) was used to evaluate Approach 1 because Approaches 2 and 3 are not applicable to particles smaller than $0.02 \mu \mathrm{m}$, as shown in Fig. 2a. In integrating Eq. (11), an equidistant diameter grid was used for discretization. Particles were assumed to be initially uncharged, monodispersed $\left(d_{\mathrm{p}}=0.003 \mu \mathrm{m}, N_{t}=10^{15} \mathrm{~m}^{-3}\right)$, with a constant ion concentration. The mobility of negative ions was slightly greater than that of positive ions, accord-

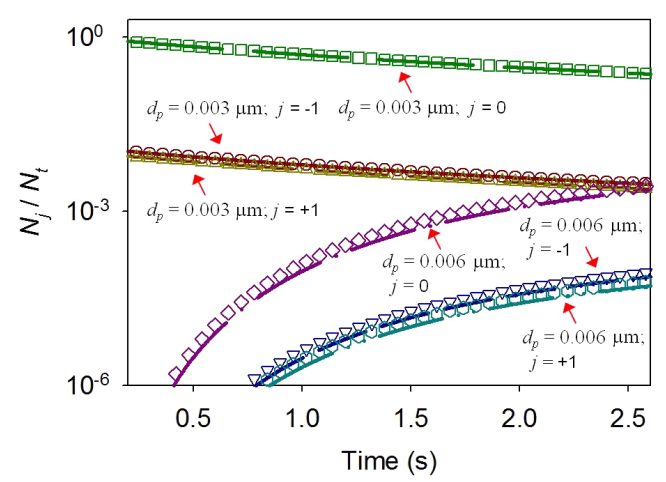

Figure 7. Validation of the numerical solution for the bivariate population balance model under a monodispersed initial condition $\left(d_{\mathrm{p}}=0.003 \mu \mathrm{m}, N_{t}=10^{15} \mathrm{~m}^{-3}\right.$, and $\left.n_{\text {ion }}^{0}=10^{18} \mathrm{~m}^{-3}\right)$. The lines and symbols represent the results of the analytical solution of Alonso (1999) and Eq. (11), respectively.

ing to the properties taken from Alonso et al. (1997) (see Table 1). Figure 7 shows the time dependent concentration of particle charge classes. The concentration of uncharged $0.003 \mu \mathrm{m}$ particles decreased with time because of loss due to coagulation and charging by captured ions. However, the loss of particle concentration caused by diffusion charging was negligible because the ion-particle attachment coefficient was small, suggesting that the time evolution of the charged-particle concentration depends on the unchargedparticle concentration. More negative than positive ions were captured by the uncharged $0.003 \mu \mathrm{m}$ particles and, thus, the concentration of the negatively charged $0.003 \mu \mathrm{m}$ particles is slightly higher than that of the positively charged $0.003-\mu \mathrm{m}$ particles. The concentrations of larger particles (e.g., charged and uncharged $0.006 \mu \mathrm{m}$ particles) increased over time because of the size growth of small particles due to coagulation, as well as the diffusion-charging mechanism. These evolution patterns predicted by Approach 1 were in good agreement with the prediction results given by the analytical approach. As can be seen in Figs. 2 and 5, the ion balance and charge balance models of Approach 1 accurately predicted the diffusion charging of nanoparticles, suggesting that the numerical solution of the bivariate population balance model (Eq. 11) reliably predicts coagulation of particles acquiring charge.

\subsubsection{Average collision efficiency of approaches 2 and 3}

Approaches 2 and 3 employ an average collision efficiency and are coupled to the monovariate, instead of the bivariate, population balance model. These approaches provided accurate particle charge distributions for various cases (e.g., Figs. 2 and 4; Kim et al., 2014), suggesting that their validity may be highly influenced by the accuracy of the average collision efficiency. Thus, we compared simulation results of 


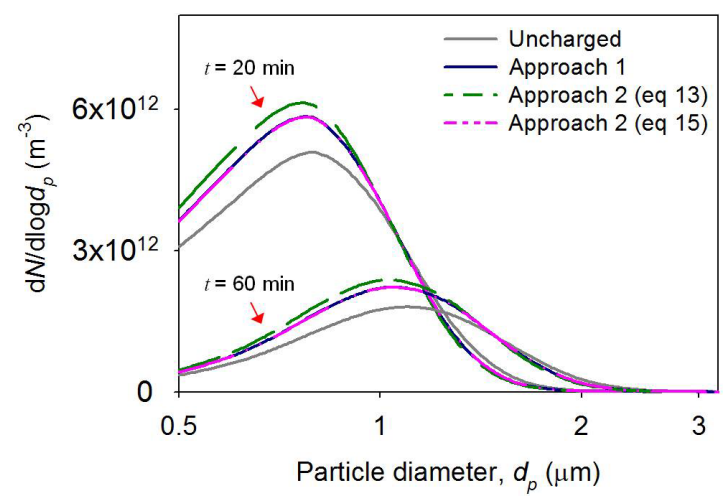

Figure 8. Time evolution of the particle size distributions predicted by the monovariate population balance model with the average collision efficiency (Eq. 15) under a monodispersed initial condition $\left(d_{\mathrm{p}}=0.5 \mu \mathrm{m}, N_{t}=10^{13} \mathrm{~m}^{-3} ; n_{\text {ion }}^{0}=10^{16} \mathrm{~m}^{-3}\right)$. Approach 1 was used as a reference that includes the mutual effect of surface charging and coagulation on the particle size and charge distributions.

Approach 2 with those of Approach 1 to check if the average collision efficiency (Eq. 15) can appropriately account for the influence of the charge distributions of particles on their size growth via coagulation. For comparison, simulation results of Approach 2 using the mean charge (Eq. 13), as well as those for uncharged particles, were included. Similarly to Oron and Seinfeld (1989a, b), we assumed monodispersed initial size distributions $\left(d_{\mathrm{p}}=0.1,0.5,1 \mu \mathrm{m}, N_{t}=10^{13} \mathrm{~m}^{-3}\right.$, and $\left.n_{\text {ion }}^{0}=10^{16} \mathrm{~m}^{-3}\right)$. The geometrical grids $\left(x_{k+1}=2 x_{k}\right)$ were used to cover a wide particle-size range. Other basic assumptions were similar to those considered for the validation test of Approach 1.

Figure 8 shows the time evolution of the particle size distributions induced by particle charging and coagulation. The simulation conditions led to the accumulation of more negative than positive charges on the particles. At $t=1 \mathrm{~min}$, the number fraction of the negatively charged particles was 0.7 , while that of the positively charged and uncharged particles was 0.16 and 0.14 , respectively. Thus, the size growth of the particles by coagulation was suppressed due to the generation of strong repulsive electrostatic forces (Approaches 1 and 2 vs. Uncharged).

While most particles were negatively charged, some particles captured positive ions. Owing to electrostatic attractive forces, the positively charged particles can more frequently coagulate with the negatively charged particles and grow. Therefore, the coagulation rates predicted by Approach 2 with the average collision efficiency were slightly higher than those for the case assuming that all particles were negatively charged (Approach 2 (Eq. 13) vs. Approach 2 (Eq. 15)). These coagulation patterns predicted by Approach 2 using the average collision efficiency were in good agreement with those given by Approach 1 (Approach 1 vs. Approach 2 (Eq. 15)), as well as the particle charge distributions in var-

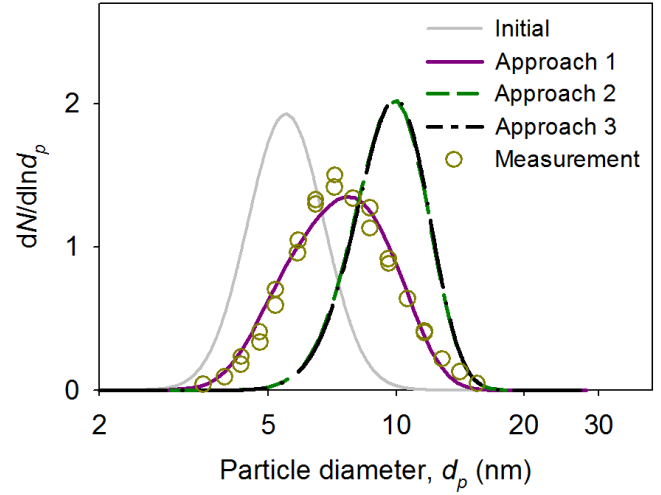

Figure 9. Evolution of the size distribution of negatively charged particles in a ${ }^{241} \mathrm{Am}$ radioactive neutralizer. For the initial condition, $d_{g}=0.0055 \mu \mathrm{m}, \sigma_{g}=1.23$, and $N_{t}=5 \times 10^{15} \mathrm{~m}^{-3}$. The lines represent the simulation result of Approach 1. The symbols are the measurements of Alonso et al. (1998).

ious size ranges (Fig. S1 in the Supplement). Similar results were obtained for different initial particle size distributions $\left(d_{\mathrm{p}}=0.1 \mu \mathrm{m} ; d_{\mathrm{p}}=1 \mu \mathrm{m}\right)$. Thus, the monovariate population balance model using the average collision efficiency can be used to simultaneously investigate charging and coagulation kinetics of atmospheric particles. These validation tests suggest that all the approaches developed can be used to reliably couple particle charging with coagulation kinetics of atmospheric particles.

\subsection{Applications}

\subsubsection{Radioactive neutralizer}

Radioactive neutralizers are typically used to control the charge of atmospheric particles in many laboratory-scale experiments. The applicability of the three approaches to studies using radioactive neutralizers was evaluated using the experiments of Alonso et al. (1998) who measured the size distribution of nanometer-size particles passing by a ${ }^{241} \mathrm{Am}$ radioactive neutralizer under various residence times.

Figure 9 shows the size distribution of negatively charged particles when the residence time, $t=0.318 \mathrm{~s}$. All particles were initially uncharged, but some particles became charged by capturing positive and negative ions in the neutralizer. Approach 1 accurately predicted the size distribution of the negatively charged particles, while the predictions by Approaches 2 and 3 were different from the measurements. The particle size distributions predicted by all the approaches were similar (not shown). It can be concluded that the Gaussian distribution used in Approaches 2 and 3 cannot accurately predict the charge distributions of very small particles (see Fig. 2). Thus, Approaches 2 and 3 should not be used for particles smaller than $0.04 \mu \mathrm{m}$.

As shown in Figs. 2-5, Approach 1 can accurately predict the charge accumulation rate of radioactive and nonradioac- 

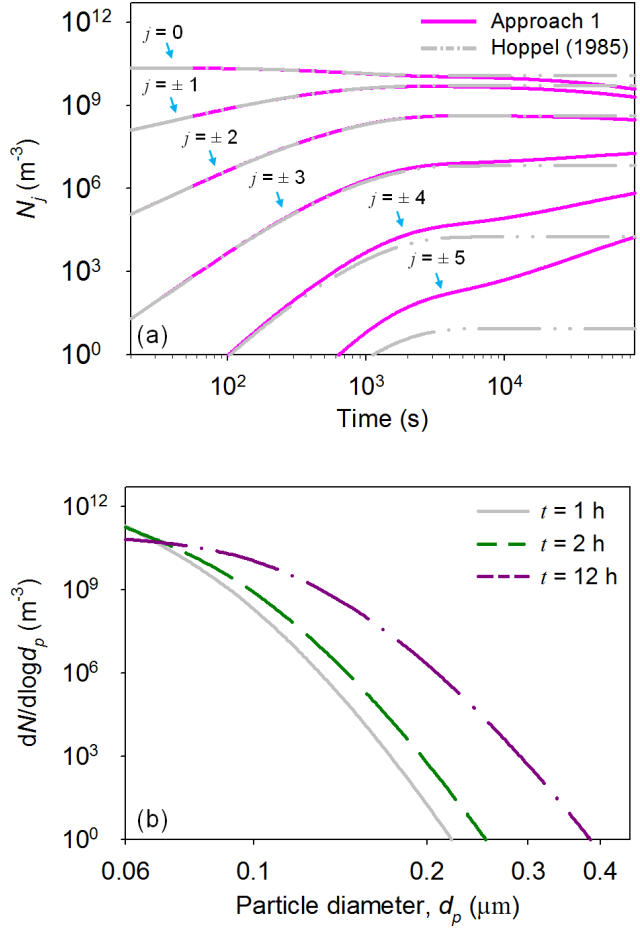

Figure 10. Time evolution of the charge (a) and size (b) distributions of atmospheric particles in the postulated atmosphere of Hoppel (1985) $\left(d_{\mathrm{p}}=0.06 \mu \mathrm{m}, N_{t}=2.3 \times 10^{10} \mathrm{~m}^{-3} ; q=\right.$ $\left.10^{7} \mathrm{~m}^{-3} \mathrm{~s}^{-1}\right)$. Approach 1 was used to involve the effects of coagulation on the Hoppel (1985) simulation.

tive particles in the free-molecule, transition, and continuum regimes. Approach 1 employs the interpolation formula of Fuchs that can be used to compute the collision frequency of the particles in these regimes, revealing that this approach can also precisely predict the charge distribution of larger particles undergoing coagulation. These results suggest that Approach 1 can be a reasonable option to simultaneously simulate charging and coagulation of particles of any size in laboratory-scale experiments.

\subsubsection{Charging and coagulation of nonradioactive particles in urban atmosphere}

Hoppel (1985) simulated charging of $0.06 \mu \mathrm{m}$ urban aerosols by diffusion charging; however, effects of coagulation on their steady-state charge distribution were excluded from the simulation. Changes in the particle charge and size distributions by charging and coagulation were investigated in this work on the basis of the simulation of Hoppel (1985) for comparison. The simulation time was approximately $100 \mathrm{~min}$, but for completeness, we repeated and extended the Hoppel (1985) simulation to 1 day. The extended results were compared with prediction results of Approach 1, which involves the effects of coagulation on the particle charge distribution. It was assumed that cosmic rays and natural

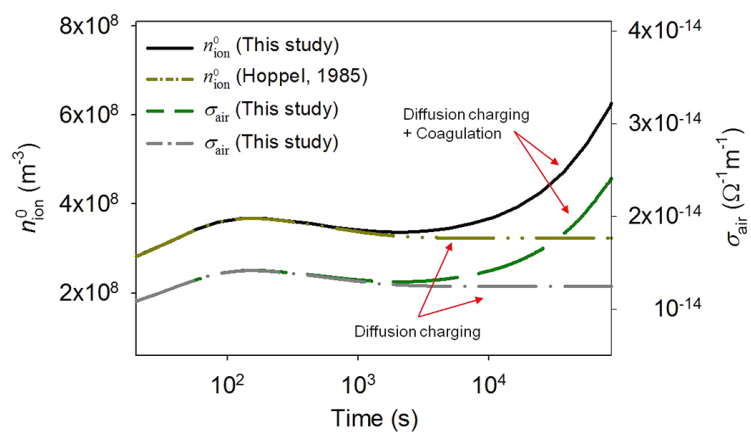

Figure 11. Time evolution of the mean ion concentration, $n_{0}$ and air conductivity, $\sigma_{\text {air }}$ in the postulated atmosphere of Hoppel (1985) $\left(d_{\mathrm{p}}=0.06 \mu \mathrm{m}, N_{t}=2.3 \times 10^{10} \mathrm{~m}^{-3} ; q=10^{7} \mathrm{~m}^{-3} \mathrm{~s}^{-1}\right)$.

radioactivity generate ion pairs in the atmosphere, giving $q_{b} \approx 10^{7} \mathrm{~m}^{-3} \mathrm{~s}^{-1}$ (Hoppel, 1985).

Figure 10 presents changes in the particle charge and size distributions vs. time. The simulation results performed by Hoppel (1985) showed that the particle charge distribution approached its steady-state value after approximately $90 \mathrm{~min}$. However, as time elapsed, the particles grew in size due to coagulation. The size growth led to the generation of large particles capturing many ions, thereby modifying the particle charge distribution.

The simulation results of Hoppel (1985) also indicated that the ion concentrations became unchanged after reaching a steady state. However, coagulation reduced the particle number concentrations which can affect the loss rate of ions by diffusion charging (see Eqs. 1 and 2). The reduction in the particle concentrations increased the ion concentrations, thereby enhancing the electrical conductivity of the postulated atmosphere (Fig. 11). The ion concentrations and electrical conductivity are expected to increase until ion-ion recombination becomes the major ion removal mechanism. These results suggest that coagulation can affect the electrical properties in the atmosphere, as well as the particle charge distribution.

\subsubsection{Charging and coagulation of radioactive particles in the atmosphere}

Comparison with results by Greenfield (1956)

Nuclear events can release particles carrying radionuclides. Greenfield (1956) simulated time evolution of the charge distribution of $0.1 \mu \mathrm{m}$ radioactive particles emitting energetic electrons at $6 \mathrm{~km}$ altitude. Because Greenfield (1956) assumed that the particle size distribution is constant for $4 \mathrm{~h}$, the influence of coagulation on the particle charge distribution was evaluated using the simulation conditions postulated by Greenfield (1956).

Figure 12 shows changes in the particle charge distributions vs. time. Both self-charging and diffusion charging in- 

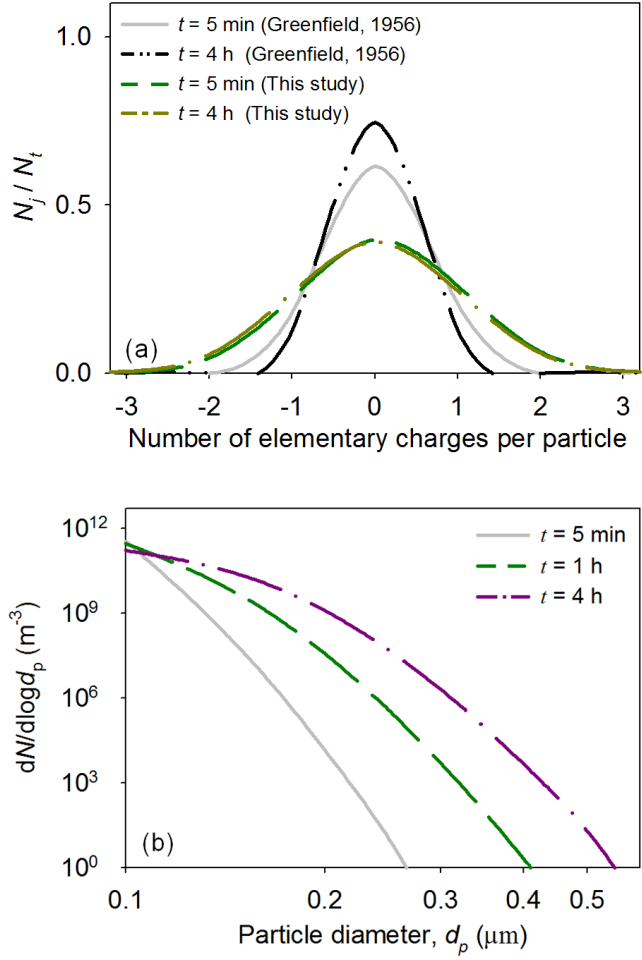

Figure 12. Time evolution of the charge (a) and size (b) distributions of monodispersed radioactive particles at $6 \mathrm{~km}$ altitude $\left(d_{\mathrm{p}}=0.1 \mu \mathrm{m}, N_{t}=3.55 \times 10^{10} \mathrm{~m}^{-3} ; I=1.5 \times 10^{4} \mathrm{~s}^{-1}\right.$, where $I$ is the ionization rate coefficient of beta-emitting radionuclides). Approach 1 was used to simultaneously simulate surface charging and coagulation of radioactive particles.

fluenced the charge accumulation on radioactive particles. Due to many ion pairs produced by beta radiation (Fig. S2), positive charge accumulated on the particles by self-charging was rapidly neutralized by capturing negative ions. Thus, the particle charge distribution given by Approach 1 was slightly shifted to the right of the zero elementary charge in Fig. 12a, although large particles with a high level of radioactivity were generated by coagulation. As time elapsed, the particle charge distribution was slightly moved to the left. Because the decay rates of the highly radioactive particles were reduced over time, their self-charging rates also decreased, and this led to the slight movement of the charge distribution to the left in Fig. 12a.

The discrepancies between the predictions of Approach 1 and Greenfield (1956) result mainly from the ion-particle attachment coefficient used in the simulation. The values assumed by Greenfield (1956) were beyond the ion-particle attachment coefficient found by other researchers (e.g., Hoppel and Frick, 1986), leading to the discrepancies observed (Kim et al., 2015).

Beta radiation caused by radioactive decay rapidly increased the ion concentrations, thereby enhancing the electrical conductivity in the atmosphere (Fig. S2). In contrast to the case shown in Fig. 11, the ion concentrations and air conductivity significantly decreased with time because the ionization rate of air molecules decreased considerably, and ion-ion recombination was responsible for the change in the concentrations. Nevertheless, the air conductivity enhancement by beta radiation was much higher than that by cosmic rays and natural radioactivity.

After the Chernobyl and Fukushima accidents, short- and long-range transport of particles carrying radionuclides, such as ${ }^{137} \mathrm{Cs}$ and ${ }^{134} \mathrm{Cs}$, affected the electrical properties of the local atmosphere in many places (Israelsson and Knudsen, 1986; Yamauchi et al., 2012). In particular, beta radiation led to significant changes in the electrical conductivity and potential gradient in the local atmosphere (Kim et al., 2015). Israelsson et al. (1987) suggested that an increase in the electrical conductivity led to enhancement of lightning activities at radioactively contaminated sites in Sweden. These observations reveal that the approaches developed in this study can be employed to investigate the influence of radionuclides on electrification phenomena in the atmosphere.

\section{Steady-state assumption of radioactive particle charging}

The steady-state assumption of particle charging can be useful to simulate coagulation of radioactive particles in model studies of radioactivity transport. Charging and coagulation kinetics of radioactive particles were investigated using Approaches 2 and 3 to evaluate the validity of the steady-state assumption of radioactive particle charging. For comparison, the size growth of particles by coagulation was simulated by assuming the Boltzmann charge distribution.

We used the simulation condition employed to validate the average collision efficiency, but additionally presumed that radioactive decay of ${ }^{134} \mathrm{Cs}$ is responsible for the ionization of air molecules. The specific radioactivity of ${ }^{134} \mathrm{Cs}$ was obtained from Clement and Harrison (1992). The ionization rate of ${ }^{134} \mathrm{Cs}$ was estimated according to Kim et al. (2015). Under these conditions, Eq. (8) revealed that $5 \tau \approx 4.3 \mathrm{~ms}$. Thus, we assumed that charge accumulation rates of ${ }^{134} \mathrm{Cs}$ particles instantaneously reach steady state, and evaluated this assumption for the simulation conditions of $X \approx 0.7$ and ion concentration given by $q_{I}=I_{\mathrm{Cs}-134} \times A_{\mathrm{Cs}-134} \times N_{t}$.

Figure 13 shows the charge and size distributions of the ${ }^{134} \mathrm{Cs}$ particles after $2 \mathrm{~h}$ of evolution. The prediction results of Approach 3 were different from those of the case assuming the Boltzmann charge distribution, but agreed well with those of Approach 2, suggesting that the steady-state assumption of radioactive particle charging can be valid if $\tau$ is small. We also tested the assumption of Approach 3 using different initial conditions (e.g., $d_{\mathrm{p}}=0.3 \mu \mathrm{m}$ ), and the agreement was still maintained (not shown). 
Table 3. Computational costs of the approaches used.

\begin{tabular}{|c|c|c|c|c|}
\hline \multicolumn{2}{|c|}{ Example: 30 size bins } & \multirow{2}{*}{$\begin{array}{r}\text { Approach } 1 \\
2\end{array}$} & \multirow{2}{*}{$\begin{array}{r}\text { Approach } 2 \\
2\end{array}$} & \multirow{2}{*}{$\begin{array}{r}\text { Approach } 3 \\
-\end{array}$} \\
\hline The number & Ion balance model & & & \\
\hline of ODEs & Charge balance model & & 30 & - \\
\hline & Population balance model & $30 \times 31=930$ & 30 & 30 \\
\hline & Total & 932 & 62 & 30 \\
\hline \multicolumn{2}{|c|}{ Computational time for urban aerosol ${ }^{\mathrm{a}, \mathrm{b}}$ (s) } & 12724.2 & 302.6 & 8.5 \\
\hline
\end{tabular}
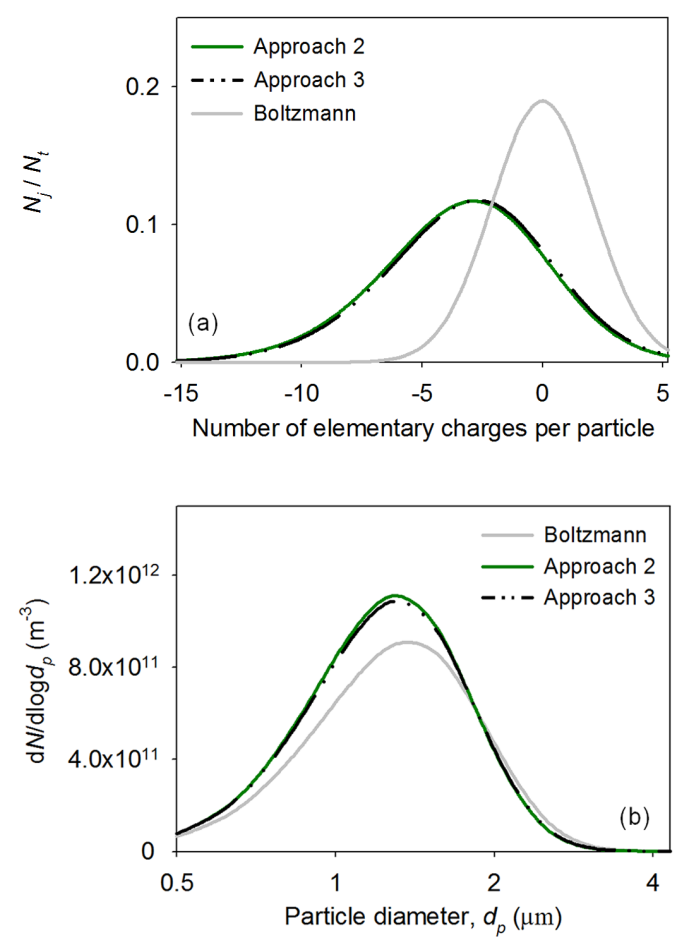

Figure 13. The charge (a) and size (b) distributions of initially monodispersed ${ }^{134} \mathrm{Cs}$ particles $\left(d_{\mathrm{p}}=0.5 \mu \mathrm{m}, A_{\mathrm{Cs}-134}=14.5 \mathrm{~Bq}\right.$; $N_{t}=10^{13} \mathrm{~m}^{-3}$ ). The simulation time is $2 \mathrm{~h}$.

\subsection{Computational costs}

The computational costs to predict transport of particles containing contaminants depends on the number of ordinary differential equations (ODEs) solved during simulation. Thus, the number of ODEs involved in the three approaches was evaluated by assuming 30 size bins, which corresponds to those used in the two-moment aerosol sectional microphysics model, covering particle diameters from 0.01 to $10 \mu \mathrm{m}$ (Adams and Seinfeld, 2002).

Table 3 shows an example of the computational costs of the three approaches. For Approach 1, we assumed that atmospheric particles can acquire up to fifteen elementary charges regardless of their sign, thereby resulting in 932
ODEs. Because Approaches 2 and 3 employed the monovariate population balance model, a fewer number of ODEs were involved in these Approaches than in Approach 1, suggesting that they are computationally more efficient. For instance, compared to Approach 1, Approaches 2 and 3 more quickly computed the charge accumulation and coagulation rates of urban aerosols.

A simple way to reduce the number of ODEs included in Approach 1 is to assume that atmospheric particles acquire only a few electrical charges. For example, Laakso et al. (2002) assumed that submicron particles can acquire elementary charges from -5 to +5 . This assumption can be valid if the particle size is small (see Fig. 2a). However, when the simulation conditions were used, we observed loss of submicron particles because they can acquire more elementary charges (Fig. S3). To preserve mass and charge, one may optimize the minimum number of elementary charges using the charge balance model of Approach 1, and then begin the simulation of charging of particles undergoing coagulation.

Approach 3 includes all the physics of charging and coagulation to predict the particle size and/or charge distribution, but, compared to Approaches 1 and 2, it is computationally more suitable for use in a 3-D global transport model to predict the transport of radioactivity in the environment after a radiological event such as a nuclear plant accident.

\section{Conclusions}

Understanding the behavior of atmospheric particles is important to accurately predict short- and long-range transport of contaminants. Particle charging and coagulation processes can strongly affect the behavior of atmospheric particles because these processes can change their important physical and electrical properties, such as size and charge. This study has shown three approaches with a wide range of complexity and applications to involve the mutual effects of charging and coagulation processes in the simulation of particle charge and size distributions vs. time. Depending on the initial conditions, these approaches can be employed to accurately predict the behavior of atmospheric particles carrying radioactive contaminants. We have shown the approaches 
to be applicable to a wide variety of atmospheric (laboratory and field) applications. The accuracy of the approaches depends on the assumptions made to reduce computational cost. The developed approaches can be readily incorporated into microphysical and transport models of any scale to account for charging phenomena of atmospheric particles.

\section{The Supplement related to this article is available online at doi:10.5194/acp-16-3449-2016-supplement.}

Acknowledgements. This work was supported by the Defense Threat Reduction Agency under grant number DTRA1-08-10BRCWMD-BAA. The manuscript has been co-authored by UT-Battelle, LLC, under Contract No. DEAC05-00OR22725 with the US Department of Energy.

Edited by: M. Kanakidou

\section{References}

Adams, P. J. and Seinfeld, J. H.: Predicting global aerosol size distributions in general circulation models, J. Geophys. Res., 107, 4370, doi:10.1029/2001JD001010, 2002.

Alonso, M.: Simultaneous charging and Brownian coagulation of nanometre aerosol particles, J. Phys. A-Math. Gen., 32, 13131327, doi:10.1088/0305-4470/32/8/003, 1999.

Alonso, M., Kousaka, Y., Nomura, T., Hashimoto, N., and Hashimoto, T.: Bipolar charging and neutralization of nanometer-sized aerosol particles, J. Aerosol Sci., 28, 14791490, doi:10.1016/S0021-8502(97)00036-0, 1997.

Alonso, M., Hashimoto, T, Kousaka, Y., Higuchi, M., and Nomura, T.: Transient bipolar charging of a coagulating nanometer aerosol, J. Aerosol Sci., 29, 263-270, doi:10.1016/S00218502(97)10007-6, 1998.

Chin, C.-J., Yiacoumi, S., and Tsouris, C: Shear-induced flocculation of colloidal particles in stirred tanks, J. Colloid Interf. Sci., 206, 532-545, doi:10.1006/jcis.1998.5737, 1998.

Clement, C. F. and Harrison, R. G.: The charging of radioactive aerosols, J. Aerosol Sci., 23, 481-504, doi:10.1016/00218502(92)90019-R, 1992.

Clement, C. F., Clement, R. A., and Harrison, R. G: Charge distributions and coagulation of radioactive aerosols, J. Aerosol Sci., 26, 1207-1225, doi:10.1016/0021-8502(95)00525-0, 1995.

Fuchs, N. A.: On the stationary charge distribution on aerosol particles in a bipolar ionic atmosphere, Geofis. Pura. Appl., 56, 185193, doi:10.1007/BF01993343, 1963.

Fuchs, N. A.: The Mechanics of Aerosols, Dover Publications, New York, 1989.

Gensdarmes, F., Boulaud, D., and Renoux, A.: Electrical charging of radioactive aerosols-comparison of the Clement-Harrison models with new experiments, J. Aerosol Sci., 32, 1437-1458, doi:10.1016/S0021-8502(01)00065-9, 2001.

Greenfield, S. M.: Ionization of radioactive particles in the free air, J. Geophys. Res., 61, 27-33, doi:10.1029/JZ061i001p00027, 1956.
Gunn, R.: Diffusion charging of atmospheric droplets by ions, and the resulting combination coefficients, J. Meteorol., 11, 339-347, doi:10.1175/1520-0469(1954)011<0339:DCOADB>2.0.CO;2, 1954.

Harrison, R. G. and Carslaw, K. S.: Ion-aerosol-cloud processes in the lower atmosphere, Rev. Geophys., 41, 1012, doi:10.1029/2002RG000114, 2003.

Hoeve, J. E. T. and Jacobson, M. Z.: Worldwide health effects of the Fukushima Daiichi nuclear accident, Energy Environ. Sci., 5, 8743-8757, doi:10.1039/C2EE22019A, 2012.

Hoppel, W. A.: Ion-aerosol attachment coefficients, ion depletion, and the charge distribution on aerosols, J. Geophys. Res., 90, 5917-5923, doi:10.1029/JD090iD04p05917, 1985.

Hoppel, W. A. and Frick, G. M.: Ion-aerosol attachment coefficients and the steady-state charge distribution on aerosols in a bipolar ion environment, Aerosol Sci. Tech., 5, 1-21, doi:10.1080/02786828608959073, 1986.

Jacobson, M. Z.: Fundamentals of atmospheric modeling, Cambridge University Press, New York, 2005.

Israelsson, S. and Knudsen, E.: Effects of radioactive fallout from a nuclear power plant accident on electrical parameters, J. Geophys. Res., 91, 11909-11910, doi:10.1029/JD091iD11p11909, 1986.

Israelsson, S., Schütte, T., Pisler, E., and Lundquist, S.: Increased occurrence of lightning flashes in Sweden during 1986, J. Geophys. Res., 92, 10996-10998, doi:10.1029/JD092iD09p10996, 1987.

Kim, Y.-H., Yiacoumi, S., Lee, I., McFarlane, J., and Tsouris, C.: Influence of radioactivity on surface charging and aggregation kinetics of particles in the atmosphere, Environ. Sci. Technol., 48, 182-189, doi:10.1021/es4047439, 2014.

Kim, Y.-H., Yiacoumi, S., and Tsouris, C.: Surface charge accumulation of particles containing radionuclides in open air, J. Environ. Radioactiv., 143, 91-99, doi:10.1016/j.jenvrad.2015.02.017, 2015.

Kumar, S. and Ramkrishna, D.: On the solution of population balance equations by discretization - I. A fixed pivot technique, Chem. Eng. Sci., 51, 1311-1332, doi:10.1016/00092509(96)88489-2, 1996.

Kweon, H., Yiacoumi, S., Lee, I., McFarlane, J., and Tsouris, C.: Influence of surface potential on the adhesive force of radioactive gold surfaces, Langmuir, 29, 11876-11883, doi:10.1021/la4008476, 2013.

Laakso, L., Mäkelä, J. M., Pirjola, L., and Kulmala, M.: Model studies on ion-induced nucleation in the atmosphere. J. Geophys. Res., 107, 4427, doi:10.1029/2002JD002140, 2002.

Liu, B. Y. and Pui, D. Y.: Equilibrium bipolar charge distribution of aerosols, J. Colloid Interf. Sci., 49, 305-312, doi:10.1016/00219797(74)90366-X, 1974.

Matsoukas, T.: The coagulation rate of charged aerosols in ionized gases, J. Colloid Interf. Sci., 187, 474-483, doi:10.1006/jcis.1996.4723, 1997.

Oron, A. and Seinfeld, J. H.: The dynamic behavior of charged aerosols: II. Numerical solution by the sectional method, J. Colloid Interf. Sci., 133, 66-79, doi:10.1016/0021-9797(89)902828, 1989a.

Oron, A. and Seinfeld, J. H.: The dynamic behavior of charged aerosols: III. Simultaneous charging and coagulation, J. Col- 
loid Interf. Sci., 133, 80-90, doi:10.1016/0021-9797(89)90283X, 1989b.

Pruppacher, H. R. and Klett, J. D.: Microphysics of Clouds and Precipitation, Kluwer Acad., Norwell, Mass., 1997.

Renard, J.-B., Tripathi, S. N., Michael, M., Rawal, A., Berthet, G., Fullekrug, M., Harrison, R. G., Robert, C., Tagger, M., and Gaubicher, B.: In situ detection of electrified aerosols in the upper troposphere and stratosphere, Atmos. Chem. Phys., 13, 11187-11194, doi:10.5194/acp-13-11187-2013, 2013.

Seinfeld, J. H. and Pandis, S. N.: Atmospheric chemistry and physics: from air pollution to climate change, John Wiley and Sons, New Jersey, 2006.

Taboada-Serrano, P., Chin, C., Yiacoumi, S., and Tsouris, C.: Modeling aggregation of colloidal particles, Curr. Opin. Colloid Interface Sci., 10, 123-132, doi:10.1016/j.cocis.2005.07.003, 2005.

Tsouris, C., Yiacoumi, S., and Scott, T.: Kinetics of heterogeneous magnetic flocculation using a bivariate populationbalance equation, Chem. Eng. Commun., 137, 147-159, doi:10.1080/00986449508936373, 1995.

Vanni, M.: Approximate population balance equations for aggregation-breakage processes, J. Colloid Interf. Sci., 221, 143-160, doi:10.1006/jcis.1999.6571, 2000.

Walker, M. E., McFarlane, J., Glasgow, D. C., Chung, E., TaboadaSerrano, P., Yiacoumi, S., and Tsouris, C.: Influence of radioactivity on surface interaction forces, J. Colloid Interf. Sci., 350, 595-598, doi:10.1016/j.jcis.2010.06.042, 2010.

Wiedensohler, A. and Fissan, H. J.: Bipolar charge distributions of aerosol particles in high-purity argon and nitrogen, Aerosol Sci. Tech., 14, 358-364, doi:10.1080/02786829108959498, 1991.

Yair, Y. and Levin, Z.: Charging of polydispersed aerosol particles by attachment of atmospheric ions, J. Geophys. Res., 94, 1308513091, doi:10.1029/JD094iD11p13085, 1989.
Yamauchi, M., Takeda, M., Makino, M., Owada, T., and Miyagi, I.: Settlement process of radioactive dust to the ground inferred from the atmospheric electric field measurement, Ann. Geophys., 30, 49-56, doi:10.5194/angeo-30-49-2012, 2012.

Yeh, H. C., Newton, G. J., Raabe, O. G., and Boor, D. R.: Selfcharging of ${ }^{198} \mathrm{Au}$-labeled monodisperse gold aerosols studied with a miniature electrical mobility spectrometer, J. Aerosol Sci., 7, 245-253, doi:10.1016/0021-8502(76)90039-2, 1976.

Yoshenko, V. I., Kashparov, V. A., Protsak, V. P., Lundin, S. M., Levchuk, S. E., Kadygrib, A. M., Zvarich, S. I., Khomutinin, X. V., Maloshtan, I. M., Lanshin, V. P., Kovtun, M. V., and Tschiervsch, J.: Resuspension and redistribution of radionucleotides during grassland and forest fires in the Chernobyl exclusion zone. Part I: fire experiments, J. Environ. Radioactiv., 86, 143-163, doi:10.1016/j.jenvrad.2005.08.003, 2006a.

Yoshenko, V. I. Kashparov, V. A., Levchuk, S. E., Glukhovskiy, A. S., Khomutni, Y. V., Protsak, V. P., Lundin, S. M., and Tschiersch, J.: Resuspension and redistribution of radionucleotides during grassland and forest fires in the Chernobyl exclusion zone. Part II: modeling the transport process, J. Environ. Radioactiv., 87, 260-278, doi:10.1016/j.jenvrad.2005.12.003, 2006b.

Yu, F. and Turco, R. P.: From molecular clusters to nanoparticles: Role of ambient ionization in tropospheric aerosol formation, J. Geophys. Res., 106, 4797-4814, doi:10.1029/2000JD900539, 2001.

Zebel, G.: Zur theorie des verhaltens elektrisch geladener aerosole, Colloid Polym. Sci., 157, 37-50, doi:10.1007/BF01734032, 1958. 